\title{
HÉRNIA DE AMYAND
}

\author{
AMYAND'S HERNIA
}

\section{Valdemir José Alegre Salles, TCBC-SP ${ }^{1}$; Deomir Germano Bassi, TCBC-SP ${ }^{2}$; Manlio Basilio Speranzini, ECBC $-\mathrm{SP}^{3}$}

\section{INTRODUÇÃO}

A hérnia de Amyand, descrita por Claudius Amyand no ano de 1786, caracteriza-se pela presença de apendicite aguda no interior do saco herniário inguinal. Este epônimo vem sendo empregado, mesmo naquelas situações em que o apêndice cecal encontra-se normal ${ }^{1}$. Esta condição é incomum, apresentando uma incidência aproximada de $0,13 \%$, com manifestação clínica variável, dependente da extensão do processo infeccioso apendicular e da presença ou não de contaminação peritoneal. Nos casos típicos encontramos um doente portador de hérnia inguinal irredutível, com quadro de escroto agudo, com celulite ou abscesso na região inguinal, ressaltando-se, entretanto, que no exame físico palpatório não identificamos sensibilidade dolorosa localizada no ponto de MacBurney ${ }^{2-3}$.

O diagnóstico pré-operatório da hérnia de Amyand é raro, sendo, na maioria dos casos, realizado durante a intervenção cirúrgica de urgência ${ }^{3}$.

$\mathrm{O}$ relato do presente caso tem o objetivo de alertar os cirurgiões, principalmente aqueles que atuam no setor de emergência, para o correto diagnóstico e tratamento desta rara condição cirúrgica.

\section{RELATO DO CASO}

Paciente do sexo masculino, de 89 anos, portador de hérnia inguinal direita há cinco anos, foi admitido no setor de emergência do Hospital Universitário da Universidade de Taubaté, referindo que há quatro dias apresentava dor abdominal localizada na fossa ilíaca direita, seguida de abaulamento doloroso e sinais flogísticos na região inguinal direita. Dos exames subsidiários solicitados, destacava-se no hemograma a presença de leucócitos: 22.000 , bastonetes: 18 e segmentados: 62; e no exame radiológico simples abdominal o padrão característico de obstrução intestinal com distensão de alças do intestino delgado localizadas predominantemente na topografia da fossa ilíaca direita.

Com o diagnóstico de hérnia inguino-escrotal direita estrangulada foi, indicada a intervenção cirúrgica de urgência, sendo iniciado a antibioticoterapia, no pré-operatório imediato, com metronidazol $500 \mathrm{mg}$ e ceftriaxona $1,0 \mathrm{~g}$ intravenosa.
Foi submetido à inguinotomia direita e após a exploração do saco herniário, identificou-se a presença do apêndice cecal necrosado e perfurado (Figura 1) associado à presença de secreção sero-purulenta envolvendo os tecidos herniados e estendendo-se até a cavidade peritoneal. Frente a este quadro, optamos pela realização de laparotomia mediana infra-umbilical.

O apêndice cecal foi reduzido para a cavidade abdominal, realizando-se a apendicectomia, de maneira clássica, sem intercorrências. O diagnóstico de apendicite aguda foi confirmado pelo exame anatomo-patológico. Empregou-se a técnica de Bassini na correção da hérnia inguinal. Optou-se pela drenagem laminar da cavidade peritoneal, por contraabertura, na região da fossa ilíaca direita e, também, do tecido celular sub-cutâneo da região inguinal direita, tendo permanecido com os drenos por sete dias, apresentando uma drenagem mínima durante este período. $\mathrm{O}$ doente apresentou

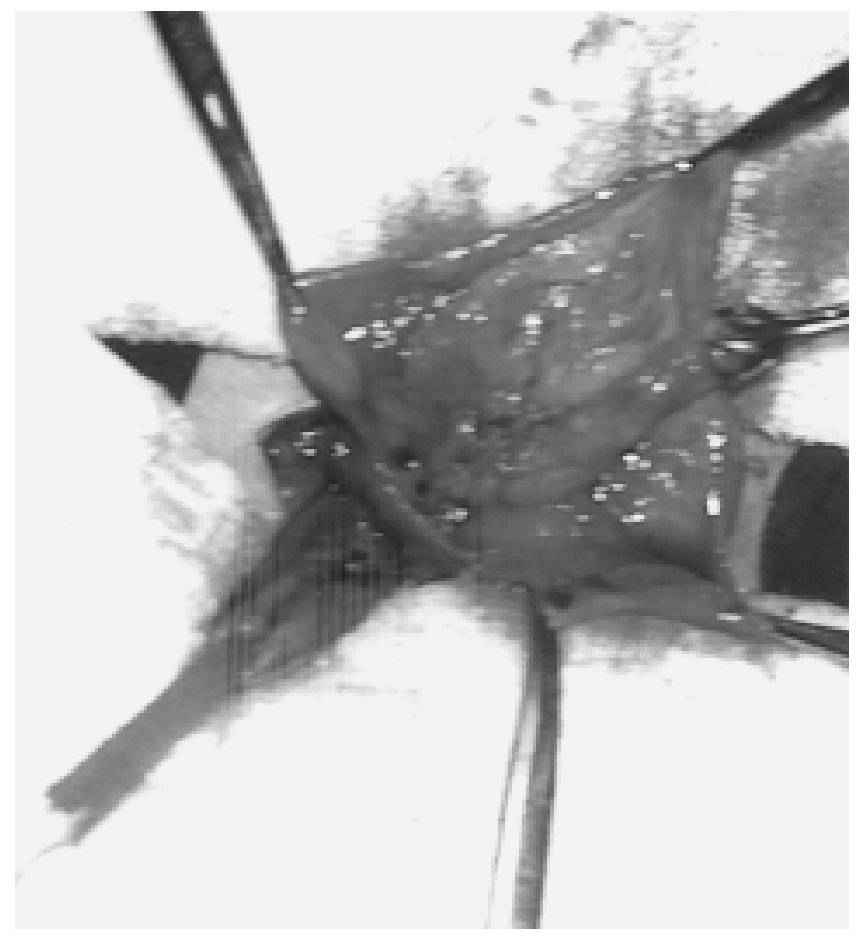

Figura 1 - Apêndice cecal no saco herniário.

1. Professor Mestre Assistente da Disciplina de Clínica Cirúrgica do Departamento de Medicina da Universidade de Taubaté.

2. Professor Doutor Titular de Cirurgia do Aparelho Digestivo do Departamento de Medicina da Universidade de Taubaté.

3. Professor Doutor Titular da Disciplina de Cirurgia do Aparelho Digestivo da Faculdade de Medicina do ABC.

Recebido em 25-05-2005

Aceito para publicação em 28-06-2005

Fonte de financiamento: nenhum

Conflito de interesses: nenhuma

Trabalho realizado no Hospital Universitário de Taubaté - SP 
evolução clínica satisfatória durante a internação, tendo alta hospitalar no $10^{\circ}$ dia de pós-operatório.

\section{DISCUSSÃO}

$\mathrm{Na}$ história natural da doença herniária, freqüentemente encontramos o encarceramento agudo ou crônico e o estrangulamento, sendo este último de intervenção cirúrgica imediata. A localização anatômica do apêndice cecal, à direita, predispõe a sua penetração nos defeitos herniários que acometem esta região ${ }^{2}$, fato observado neste caso, cuja manifestação clínica principal era de uma hérnia inguinoescrotal estrangulada, tendo sido encontrado o apêndice cecal como única víscera herniada.

Nos casos de dor pélvica aguda e de escroto agudo, o emprego da tomografia computadorizada pélvica pode demonstrar a presença de hérnia encarcerada associada à apendicite aguda, sendo considerado o melhor método diagnóstico de imagem ${ }^{2-4}$. Neste caso, o exame tomográfico não foi realizado, inicialmente porque não faz parte da rotina do nosso serviço a sua utilização no diagnóstico diferencial das afecções inguino-crurais agudas e também porque o seu emprego não alteraria a indicação cirúrgica emergencial, ressaltando-se, entretanto, que possibilitaria a equipe médica o correto diagnóstico pré-operatório da doença.
Quando ocorre a associação da apendicite aguda na hérnia inguinal encarcerada ou estrangulada, a cirurgia de apendicectomia pode ser realizada pela própria incisão da inguinotomia, porém, como identificamos a presença de secreção purulenta na região inguinal, estendendo-se por além do anel inguinal interno até a pelve, optamos pela ampliação do acesso à cavidade peritoneal realizando uma laparotomia mediana infra-umbilical, visando com isso à adequada limpeza desta cavidade. A redução do conteúdo herniado para o interior da cavidade peritoneal possibilitou a realização da apendicectomia pela técnica clássica e a remoção da secreção purulenta de maneira satisfatória. Após o fechamento convencional da cavidade peritoneal abordamos o defeito herniário inguinal e optamos pelo emprego da técnica de Bassini na sua correção, não tendo feito uso de qualquer prótese, uma vez que a utilização de material sintético está contra-indicada nesta situação devido à contaminação bacteriana tecidual local e da cavidade peritoneal, pelo processo infeccioso apendicular ${ }^{3,5}$.

Além da raridade deste tipo de hérnia, achamos importante o seu relato, pois a lembrança da associação entre a hérnia inguinal direita estrangulada e a apendicite aguda, ajudará a comunidade médica afeita ao tratamento desta afecção, na sua correta conduta terapêutica desta emergência cirúrgica.

\begin{abstract}
Amyand's hernia is an extremely rare surgical event. It is characterized by the presence of acute appendix in an incarcerated inguinal hernia. Its clinical presentation varies, depending on the extent of appendicular inflammation. The authors report a case of Amyand's hernia, in an 89 years-old male who had the diagnosis made intraoperatively (Rev. Col. Bras. Cir. 2006; 33(5): 339-340).
\end{abstract}

Key words: Hernia; Appendicitis; Acute diseases.

\title{
REFERÊNCIAS
}

1 - Lyass S, Kim A, Bauer J. Perforated appendicitis within an inguinal hernia: case report and review of literature. Am J Gastroenterol. 1997; 92(4):700-2.

2 - House MG, Goldin SB, Chen H. Perforated Amyand's hernia. South Med J. 2001; 94(5):496-8.

3 - D’Alia C, Lo Schiavo MG, Tonante A. Amyand's hernia: case report and review of the literature. Hernia. 2003; 7(2):89-91.

4 - Luchs JS, Halpern D, Katz DS. Amyand's hernia: prospective CT diagnosis. J Comput Assist Tomogr. 2000; 24(6):884-6.

5 - Logan MT, Nottingham JM. Amyand's hernia: a case report of an incarcerated and perforated appendix within an inguinal hernia and review of the literature. Am Surg. 2001; 67(7):628-9.
Como citar este artigo:

Salles VJA, Bassi DG, Speranzini MB. Hérnia de Amyand. Rev Col Bras Cir. [periódico na Internet] 2006 set-Out; 33(5). Disponível em URL: http://www.scielo.br/rcbc

Endereço para correspondência:

Dr. Valdemir José Alegre Salles.

Rua José Bonani, 199

Independência,

12031-260 - Taubaté - sp.

e-mail: valiris@ vivax.com.br 